\title{
Micromechanical finite element parametric study of polyamide 6 based single polymer composites reinforced by woven textile structures
}

\author{
Shafagh D. Tohidi ${ }^{\mathrm{a}, *}$, Ana Maria Rocha ${ }^{\mathrm{a}}$, Bernhard Engesser ${ }^{\mathrm{c}}$, Nadya V. Dencheva ${ }^{\mathrm{b}}$, \\ Zlatan Denchev ${ }^{\mathrm{b}}$ \\ ${ }^{a}$ Center of Textile Science and Technology (2C2T), Department of Textile Engineering, University of Minho, Guimarães, Portugal \\ ${ }^{\mathrm{b}}$ IPC - Institute for Polymers and Composites, Department of Polymer Engineering, University of Minho, Guimarães, Portugal \\ ${ }^{\mathrm{c}}$ Jakob Müller AG, Frick, Switzerland
}

\section{A R T I C L E I N F O}

\section{Keywords:}

Single polymer composite

Woven reinforcements

Tensile properties

Impact strength

Finite element analysis

\begin{abstract}
A B S T R A C T
This study presents a finite element-based micromechanical analysis of woven single polymer composites (WSPC), prepared by compression molding from polyamide 6 (PA6) woven fabrics powder-coated with PA6 microparticles. Initially, the PA6 microparticles (MP) were synthesized by solution/precipitation activated anionic ring-opening polymerization of $\varepsilon$-caprolactam. After the powder coating, the MP fraction upon each textile ply was transformed into the continuous PA6 matrix by hot pressing at a temperature lower than the melting of the PA6 textile reinforcements. Plain and satin PA6 woven fabrics were selected as reinforcements that were stretched and annealed prior to molding so as to enhance their mechanical performance. The tensile and Izod impact properties of WSPC were characterized in relation to the reinforcement architecture, fiber content and ply orientation. Finite element analysis was used for a parametric study of woven reinforcements and to correlate the deformation and stress distribution of the structures with the tensile failure of the composites. Moreover, to assess the interfacial matrix-reinforcements bonding state, a study of the surfaces fracture, obtained by SEM topography, using image processing was performed.
\end{abstract}

\section{Introduction}

Single polymer composites (SPC) are novel promising composite materials wherein reinforcements are of the same polymer from which the matrix is made [1]. In SPC, the adhesion between the matrix and reinforcements is increased due to the possibility of non-covalent or even covalent bonding across the interface leading to a better stress transfer in such composites [2]. The key benefit of SPC is their full recyclability by reprocessing [3], which attracts the interest of highvalue industrial sectors. To produce most SPC types, melt-processing techniques are frequently used, such as powder impregnation, hot compaction, partial melting, film-stacking or co-extrusion [4-8]. A typical drawback of these methods is the narrow processing window, resulting in partial melting and loss of orientation of the reinforcements, unavoidably leading to insufficient mechanical properties [2]. There are various studies dealing with the tensile properties and widening the processing window of polyamide 6 (PA6)-based SPC [7,9-11].

The influence of the reinforcement structural parameters, such as the geometry of textile fabric, crimp ratio, and aspect ratio, on the mechanical properties of composite materials have long taken the attention of many researchers [12-21]. However, the interconnection between reinforcement's geometrical parameters and mechanical properties of woven reinforced PA6-based SPC and precursors have not yet been investigated.

The influence of crimp in woven reinforcements on the longitudinal stiffness of carbon fiber composite was studied by Stig and Hallstrom [22]. Their results revealed that the influence of crimp on the longitudinal stiffness is substantial and the stiffness decreases non-linearly with increasing crimp. Potluri et al. [23] investigated the effect of the crimp ratio of woven fabrics on the tensile stiffness and strength of plain-woven glass/polyester composite material. They found out that the crimp interchange takes place in the direction of the loading. The crimp value decreases in the loading direction and increases in the transverse direction whenever the tensile loads are applied uniaxially.

$\mathrm{Xu}$ et al. [20] investigated the influence of plain and interlock woven reinforcements' geometry on the damping (vibrational response) of fiberglass-based composites. They found out the strong influence of woven structure, fiber volume fraction and resin-rich on the performance of the composites in vibration. Houshyar et al. [21] studied the

\footnotetext{
* Corresponding author.

E-mail address: id4618@alunos.uminho.pt (S.D. Tohidi).
} 
effect of woven architectures on the mechanical moduli of single-lamina polypropylene-ethylene random copolymer-based composites. Their results depicted that the plain weave composites exhibited storage moduli about four times higher than those reinforced with satin structures, which was in accordance with the better viscous behavior and impact resistance of the former.

This study is focused on the relation between mechanical performance and the geometry of plain and satin woven reinforcements in polyamide 6 based single polymer composites (WSPC). To produce the WSPC, all textile plies were powder-coated by PA6 microparticles (MP), previously synthesized via activated anionic ring opening polymerization (AAROP) of $\varepsilon$-caprolactam (ECL) in suspension and consolidated under the optimized regime. This production procedure is denominated by PCCM (powder coating-compression molding). The overall tensile and Izod impact properties of these WSPC were studied as a function of the woven architecture, ply orientation and fiber volume fraction. To connect the effect of woven reinforcement geometry, with the overall tensile properties of WSPC, a three-dimension real size models of woven reinforcements were simulated and mechanically analyzed using finite element analysis. The bonding state at the reinforcement/matrix interface was analyzed using image processing techniques and then related to the overall tensile properties of WSPC.

\section{Material and experimental test method}

\subsection{Woven reinforcements}

Plain and satin woven fabrics made of air jet textured PA6 continuous filaments (160 dtex) were selected and pre-washed with a nonionic detergent solution at $30^{\circ} \mathrm{C}$ for $30 \mathrm{~min}$ to remove contaminations and then rinsed with reverse osmosis water for another $15 \mathrm{~min}$. All woven reinforcements were immersed in puriss acetone (SigmaAldrich) for $30 \mathrm{~min}$ and then dried for $120 \mathrm{~min}$ at $60{ }^{\circ} \mathrm{C}$ to eliminate any non-chemically bonded hydrophobic finish (oligomers) from the surface of the filament. To improve the mechanical properties and geometrical stability, all reinforcements were extended biaxially to $30 \%$ of their original length using a specially designed metal frame and a screen stretching apparatus (Fig. 1). The extended reinforcements were then annealed at $170{ }^{\circ} \mathrm{C}$ for $90 \mathrm{~min}$ with the fixed ends.

The geometrical characteristics of the woven reinforcements in this study, with and without stretching-annealing treatment, are tabulated in Table 1.

\subsection{Preparation of WSPC}

The PA6 MP was synthesized by applying the solution-precipitation AAROP of ECL, which polymerization procedure is covered in detail in previous studies $[24,25]$. To produce the WSPC with different reinforcement architectures (plain and satin), fiber volume fractions (15, 20 and 25\%) and plies orientation (warp and weft), the PCCM technique was employed. For composite consolidation, a Moore hydraulic hot press (United Kingdom) with a $70 \times 70 \times 2 \mathrm{~mm}$ mold dimension was utilized. Mold pressure and temperature were set to $5 \mathrm{MPa}$ and $215{ }^{\circ} \mathrm{C}$, respectively, applied for $10 \mathrm{~min}$. The temperature of compression molding is kept below the $\mathrm{T}_{\mathrm{m}}$ of the PA6 woven reinforcements and above that of the MP. Subsequently, the molded laminate composites were cooled down to $50{ }^{\circ} \mathrm{C}$ at a rate of ca. $40^{\circ} \mathrm{C} / \mathrm{min}$. Table 2 shows all samples designation and specifications.

\subsection{Mechanical characterization}

The method of ASTM D5034 standard (grab test) was selected for the tensile tests of woven reinforcements $(150 \times 100 \mathrm{~mm})$, using an Instron 4505 machine with a standard load cell of $2.5 \mathrm{kN}$ and at a crosshead speed of $2 \mathrm{~mm} / \mathrm{min}$.

To study the impact failure mechanism, as well as to measure the compression stiffness of the WSPC, dynamic mechanical analysis (DMA) was performed based on ASTM D4065-01 standard on a DMA 8000 apparatus (Perkin Elmer, USA). The following equations were considered to calculate the viscoelastic parameters, compression stiffness $\left(E^{*}\right)$, elastic (storage) modulus ( $\left.E^{\prime}\right)$, viscous (loss) modulus $\left(E^{\prime}\right)$ and tangent delta $(\tan \delta)$ in an isothermal condition $\left(30^{\circ} \mathrm{C}\right)$.

$\left\{\begin{array}{l}E^{\prime}=\frac{\sigma_{0}}{\varepsilon_{0}} \times \cos \delta \\ E^{\prime^{\prime}}=\frac{\sigma_{0}}{\varepsilon_{0}} \times \sin \delta \\ E^{*}=E^{\prime}+i E^{\prime \prime}\end{array}\right.$

where the $\sigma_{0}, \varepsilon_{0}$ and $\delta(\mathrm{rad})$ are the sinusoidal stress, the resulting strain and the phase difference between the dynamic stress and strain, respectively [26].

The tensile tests of composites were performed according to ASTM D638 using the same tensile testing machine equipped with a standard load cell of $50 \mathrm{kN}$, at a crosshead speed of $2 \mathrm{~mm} / \mathrm{min}$ and a gauge length of $38 \mathrm{~mm}$. Normalized test specimens were stored for 30 days at $23{ }^{\circ} \mathrm{C}$ and $65 \%$ relative humidity before testing and then cut by laser
Satin (5 harness)

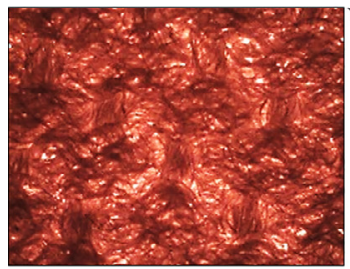

Stretching- Annealing

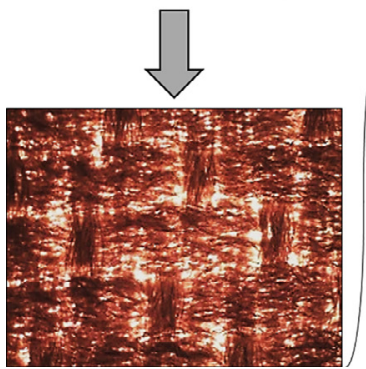

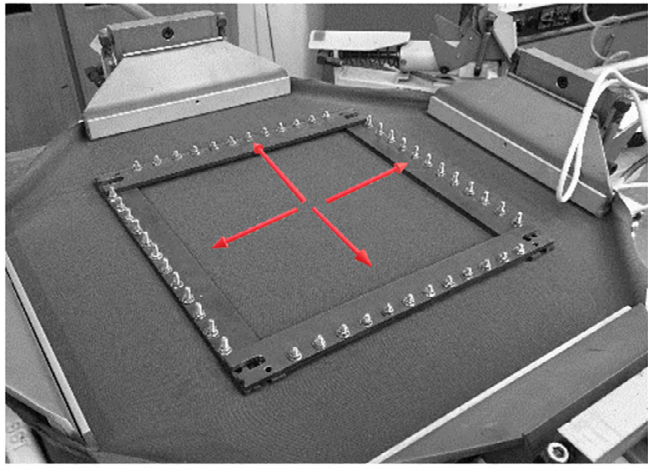

Biaxial stretching aparatus
Plain

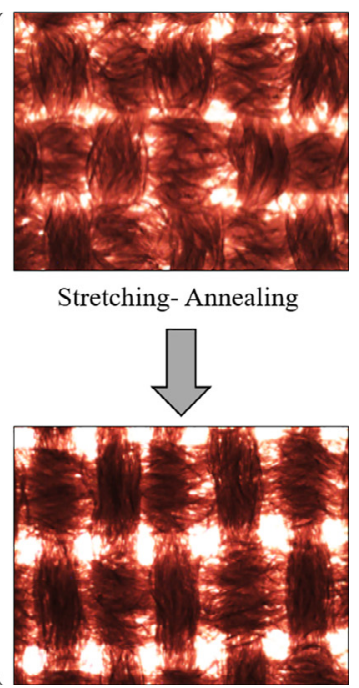

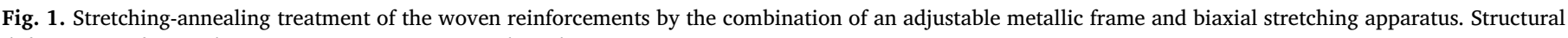
deformation of treated woven structures is presented on the images. 
Table 1

Sample designation and properties of plain and satin reinforcements.

\begin{tabular}{|c|c|c|c|c|c|c|}
\hline Reinforcement & Treatment & Sample designation & Warp density (filaments/cm) & Weft density (filaments/cm) & Areal weight $\left(\mathrm{g} / \mathrm{m}^{2}\right)$ & Thickness (mm) \\
\hline \multirow[t]{2}{*}{ Plain } & No & $\mathrm{P}(0$ or 90$)$ & 22 & 16 & $147.6 \pm 1.7$ & $0.58 \pm 0.01$ \\
\hline & Yes & $\mathrm{P}(0$ or 90$)-\mathrm{A}$ & 20 & 12 & $111.0 \pm 2.1$ & $0.42 \pm 0.01$ \\
\hline \multirow[t]{2}{*}{ Satin (5 harness) } & No & $S(0$ or 90$)$ & 22 & 16 & $142.4 \pm 2.3$ & $1.00 \pm 0.02$ \\
\hline & Yes & $S(0$ or 90$)-A$ & 22 & 12 & $106.5 \pm 1.6$ & $0.46 \pm 0.01$ \\
\hline
\end{tabular}

Note: 0 and 90 stand for warp and weft directions respectively.

Table 2

The designation of WSPC composite laminates reinforced with plain and satin structures.

\begin{tabular}{lll}
\hline Sample designation & $V_{f}, \%$ & Plies Number \\
\hline PU-P or S ${ }^{\mathrm{b}}\left({ }^{\mathrm{a}}\right)-15$ & 15 & 3 \\
PU-P or S ${ }^{\mathrm{b}}\left({ }^{\mathrm{a}}\right)-20$ & 20 & 4 \\
PU-P or S ${ }^{\mathrm{b}}\left({ }^{\mathrm{a}}\right)-25$ & 25 & 5 \\
\hline
\end{tabular}

${ }^{\text {a }}$ Unidirectional laminating of woven textile reinforcements in which $0^{\circ}$ and $90^{\circ}$ stand for warp and weft directions respectively.

${ }^{\mathrm{b}} \mathrm{P}$ and $\mathrm{S}$ represent plain and satin reinforcements respectively.

from one and the same composite plate. At least five specimens of each sample were tested.

The impact strength of the unnotched WSPC was measured via the Izod pendulum impact tester, according to ASTM D 256-04 standard. The strike point was set at $22 \mathrm{~mm}$ height. Eq. (3) was used to calculate the impact strength (IS) of the WSPC.

$\operatorname{IS}\left(\frac{K J}{m^{2}}\right)=\frac{E_{W S P C}-E_{0}}{\mathrm{~A}}$

where A, $E_{0}$ and $E_{W S P C}$ are the area of the sample, the impact energies registered without and with the sample, respectively [27].

\subsection{3-D real-size simulation of reinforcements}

To perform the numerical analysis and geometrical-mechanical studies, the real-size structures of the treated woven reinforcement were modeled. The Kemp racetrack model [28] was used as a reference, in which the base points of reinforcements' kernel geometry were drawn via analysis of the technical surface of ten digitalized microscopic images, using MATLAB ${ }^{\circ}$ software. Subsequently, a CATIA ${ }^{\circ}$ (V5 R18, Dassault system, France) software was employed to sweep the filaments profile along the kernel geometry. Finally, a virtual clash test was performed to evaluate the contact state on each interlacing point (Fig. 2). To simplify the models, three major assumptions were considered: (i) The filament cross section was elliptical; (ii) The sweeping of the elliptical cross-section through the kernel geometry was constant and (iii) No dimensional deformation occurred at cross-over points.

\subsection{Microscopy studies and image processing}

The scanning electron microscopy (SEM) studies were carried out in a NanoSEM-200 apparatus of FEI Nova (USA) using mixed secondary electron/back-scattered electron in-lens detection. Au/Pd alloy was applied to sputter-coat the samples to be observed. To visualize and image analyze the aspect ratio of the embedded filaments, optical microscopy images of WSPC prepared by microtoming, were obtained by an Olympus BH-2 light microscope (Japan) equipped with Leica Application Suite 4 software.

To analyze the fracture surface of WSPC, image processing techniques were applied. The SEM images from the surface fracture of all composites were imported into MATLAB ${ }^{\circ}$ program to plot the contour graphs. The image segmentation techniques were used for better evaluation of the reinforcement/matrix bonding state after tensile failure.

\subsection{Finite element analysis}

A parametric study on von Mises stress distribution along a $15 \times 15 \mathrm{~mm}$ constitutive model of stretched-annealed woven reinforcements was performed during tensile straining (5\%) using finite element analysis. The filaments directional properties were implemented using the implicit mode of ABAQUS standard ${ }^{\mathrm{Tm}}$ (version 6.12, Dassault system, France) software. Through the entire models, compatible tetrahedral meshes were applied using the four-node tetrahedral element (C3D4) with the edge seeding of $0.05 \mathrm{~mm}$ [29].

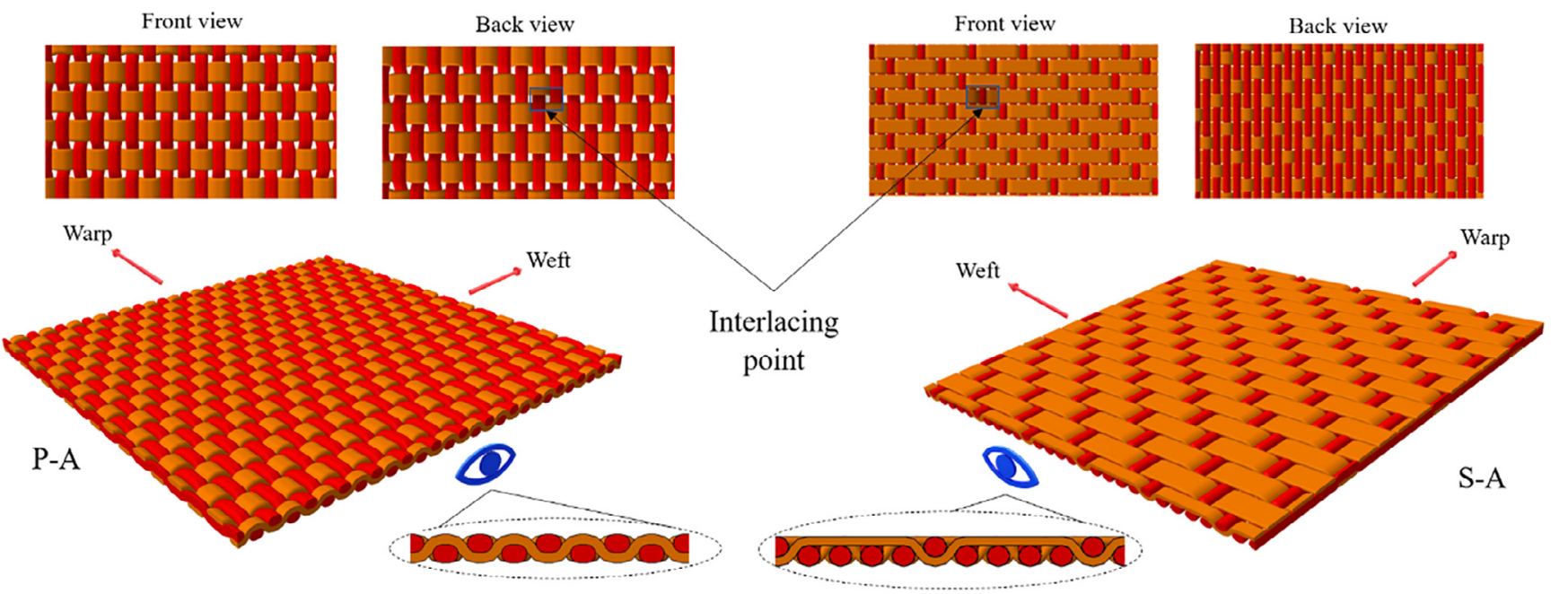

Fig. 2. Simulated real size model of P-A and S-A reinforcements based on Kemp racetrack model [28]. For sample designation see Table 1. 
Table 3

Tensile properties of the treated woven reinforcements. For sample designation see Table 1.

\begin{tabular}{lllll}
\hline Specimens & $\begin{array}{l}\text { Tensile Stiffness } \\
\text { E (MPa) }\end{array}$ & $\begin{array}{l}\text { Tensile Strength } \\
\sigma_{\max }(\mathrm{MPa})\end{array}$ & $\begin{array}{l}\text { Strain at } \\
\text { rupture } \\
\varepsilon_{\text {break }}(\%)\end{array}$ & $\begin{array}{l}\text { Poisson } \\
\text { ratio } \\
v\end{array}$ \\
\hline $\mathrm{P}(0)$ & $0.8 \pm 0.1$ & $15.4 \pm 0.8$ & $67.2 \pm 0.7$ & 0.97 \\
$\mathrm{P}(90)$ & $2.2 \pm 0.2$ & $17.4 \pm 0.4$ & $61.1 \pm 1.8$ & 0.80 \\
$\mathrm{P}(0)-\mathrm{A}$ & $21.7 \pm 1.1$ & $19.4 \pm 1.0$ & $28.1 \pm 1.0$ & 0.41 \\
$\mathrm{P}(90)-\mathrm{A}$ & $3.4 \pm 0.3$ & $19.0 \pm 1.0$ & $46.2 \pm 1.4$ & 0.35 \\
$\mathrm{~S}(0)$ & $0.9 \pm 0.1$ & $8.1 \pm 0.2$ & $65.0 \pm 1.4$ & 1.16 \\
$\mathrm{~S}(90)$ & $0.8 \pm 0.1$ & $9.3 \pm 0.6$ & $66.9 \pm 0.8$ & 1.45 \\
$\mathrm{~S}(0)-\mathrm{A}$ & $43.2 \pm 1.7$ & $3.4 \pm 0.1$ & $10.0 \pm 0.8$ & 1.08 \\
$\mathrm{~S}(90)-\mathrm{A}$ & $1.4 \pm 0.1$ & $16.5 \pm 1.0$ & $45.1 \pm 1.5$ & 1.23 \\
\hline
\end{tabular}

* The magnitude of $v$ was measured at the tensile strain range between 0 and 5 $\varepsilon \%$.

\section{Results and discussion}

\subsection{Mechanical properties of woven reinforcements}

Table 3 shows the tensile properties of woven reinforcements before and after the stretching-annealing treatment, in warp and weft directions. The treatment significantly improved the tensile stiffness and strength of all reinforcements. The S-A structures showed higher Emodulus (ca. 99\%) than P-A samples in the warp direction $\left(0^{\circ}\right)$. The reason lies on the larger filamenst's floats (straight filaments) in S-A structures as compared to the P-A reinforcements. The tensile strength of P-A reinforcements was higher than S-A structures, ca. $471 \%$ and $15 \%$ in the warp and weft directions, respectively. From the obtained results, it is apparent that the S-A structures depict a more anisotropic tensile behavior due to the significant differences between their tensile properties in both directions, which can be explained by the different structural geometry promoted by the weave pattern.

The compression properties of woven reinforcements were carried out via dynamic mechanical analysis (DMA) and provided quantitative information about their influence in the WSPC during the impact test. Fig. 3 depicts the measured viscoelastic parameters, such as storage modulus $\left(E^{\prime}\right)$, loss modulus $\left(E^{\prime \prime}\right)$ and the calculated complex compression modulus ( $\left.E^{*}\right)$ using Eq. (1). As it can be seen in Fig. 3, P-A reinforcements show remarkably higher compression stiffness than the $S$ A structures. The reason lies on the existence of float filaments (lower filament's crimp) in a satin pattern which causes compressive behavior of these reinforcements.

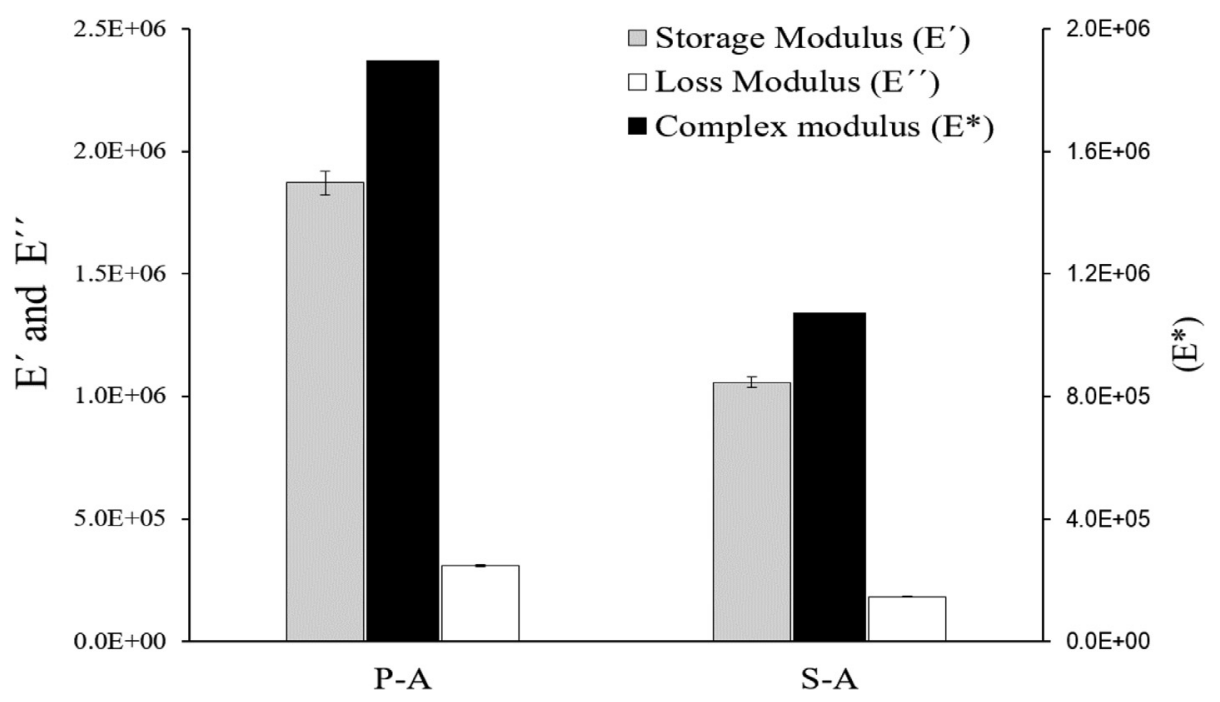

Fig. 3. Dynamic mechanical analysis (DMA) of woven reinforcements after stretching-annealing treatment. For sample designation see Table 1.
Table 4

Tensile properties of WSPC in relation to the reinforcement's architecture, fiber content and test direction: i) Elastic modulus, E (GPa); ii) Stress at max, $\sigma_{\max }$ (MPa); iii) Stress at break, $\sigma_{\text {break }}(\mathrm{MPa})$; iv) Strain at break, $\varepsilon_{\text {break }}(\%)$. For sample designation see Table 2 .

\begin{tabular}{lllll}
\hline Specimens & $\mathrm{E}(\mathrm{GPa})$ & $\sigma_{\max }(\mathrm{MPa})$ & $\sigma_{\text {break }}(\mathrm{MPa})$ & $\varepsilon_{\text {break }}(\%)$ \\
\hline PN & $1.73 \pm 0.02$ & $56.7 \pm 1.8$ & $56.7 \pm 1.7$ & $5.2 \pm 0.1$ \\
PU-P(0)-15 & $2.57 \pm 0.03$ & $61.7 \pm 1.1$ & $55.7 \pm 1.6$ & $10.7 \pm 0.5$ \\
PU-P(90)-15 & $1.64 \pm 0.06$ & $37.9 \pm 0.8$ & $37.9 \pm 0.8$ & $3.9 \pm 0.2$ \\
PU-P(0)-20 & $2.18 \pm 0.04$ & $51.1 \pm 1.8$ & $51.1 \pm 1.8$ & $11.3 \pm 0.5$ \\
PU-P(90)-20 & $2.25 \pm 0.05$ & $49.6 \pm 0.7$ & $46.9 \pm 0.6$ & $9.6 \pm 0.8$ \\
PU-P(0)-25 & $2.41 \pm 0.05$ & $54.3 \pm 1.0$ & $53.9 \pm 0.6$ & $11.3 \pm 0.8$ \\
PU-P(90)-25 & $2.49 \pm 0.06$ & $56.4 \pm 1.3$ & $55.9 \pm 0.7$ & $7.2 \pm 0.3$ \\
PU-S(0)-15 & $2.50 \pm 0.02$ & $48.9 \pm 1.1$ & $46.3 \pm 1.3$ & $6.6 \pm 0.1$ \\
PU-S(90)-15 & $2.22 \pm 0.05$ & $47.8 \pm 0.1$ & $46.1 \pm 1.3$ & $6.5 \pm 0.3$ \\
PU-S(0)-20 & $2.40 \pm 0.04$ & $54.1 \pm 1.9$ & $53.8 \pm 1.8$ & $7.4 \pm 0.2$ \\
PU-S(90)-20 & $1.98 \pm 0.03$ & $38.4 \pm 0.5$ & $38.2 \pm 0.7$ & $4.5 \pm 0.4$ \\
PU-S(0)-25 & $2.42 \pm 0.01$ & $51.9 \pm 1.6$ & $51.9 \pm 0.9$ & $7.0 \pm 0.3$ \\
PU-S(90)-25 & $2.27 \pm 0.02$ & $57.0 \pm 1.3$ & $57.0 \pm 1.2$ & $6.1 \pm 0.2$ \\
\hline
\end{tabular}

\subsection{Mechanical characterization of WSPC}

The representative parameters of the tensile stress-strain curves of WSPC are shown in Table 4, wherein the influence of reinforcement orientation, architecture and fiber volume fraction is assessed. In case of warp direction, the plain and satin reinforced WSPC with 15\% fiber content showed significant improvement on their tensile stiffness, about ca. $49 \%$ and $40 \%$ respectively when compared to PN matrix reference. Regarding the direction of tensile loads, satin reinforced WSPC shows superior tensile stiffness in warp than weft direction. Although, in the case of plain reinforced WSPC, regardless to the composites with $V_{f}=15 \%$, all samples demonstrated higher elastic modulus in weft direction. Generally, the tensile strength $\left(\sigma_{\max }\right)$ of WSPC in warp direction is comparable or slightly lower than PN. However, increasing the fiber content up to $V_{f}=25 \%$ raised the stress at max magnitude for WSPC reinforced in weft direction (Table 4). It was found that only the PU-P (0)-15 sample showed higher tensile strength than the PN matrix. The plain reinforced WSPC demonstrates the higher ductility due to the greater $\varepsilon_{\text {break }}$ value as compared with the composites reinforced with satin structures. As a conclusion, with respect to the tensile moduli and strength parameters, plain and satin reinforced WSPC performed in a comparable way and the differences are in the margin of the error.

The longitudinal/transversal ratio of composite's tensile properties in relation with the reinforcement's architecture and fiber content are presented in Table 5 and designated by the degree of tensile anisotropy

$\square$ Loss Modulus (E")

Complex modulus (E*) 
Table 5

The degree of tensile anisotropy (DA) in WSPC in relation to the reinforcement's architecture, fiber volume fraction.

\begin{tabular}{lllll}
\hline Specimens & $D A_{E}$ & $D A_{\sigma_{\text {max }}}$ & $D A_{\sigma_{\text {break }}}$ & $D A_{\varepsilon_{\text {break }}}$ \\
\hline PU-P-15 & 1.57 & 1.63 & 1.47 & 2.73 \\
PU-P-20 & 0.97 & 1.03 & 1.09 & 1.17 \\
PU-P-25 & 0.97 & 0.96 & 0.96 & 1.57 \\
PU-S-15 & 1.13 & 1.02 & 1.00 & 1.02 \\
PU-S-20 & 1.21 & 1.41 & 1.41 & 1.64 \\
PU-S-25 & 1.07 & 0.91 & 0.91 & 1.15 \\
\hline
\end{tabular}

(DA). By comparing DA values, it can be deduced that embedding the balanced architecture (i.e. P-A structure) causes the isotropic tensile behavior of WSPC whereas the unbalanced geometry (i.e. S-A reinforcement) yields uneven stress distribution along the filaments in either principal direction which led to orthotropic properties of S-A reinforced WSPC. A more detailed study is presented in the next section using finite element analysis.

The impact resistance (IS) of WSPC was studied and compared with the PN neat matrix reference sample and the results are presented in the radar chart, shown in Fig. 4. The inner orbit with 0 index (green line) represents the reference value (Fig. 4). The outer line (red line) displays the impact resistance improvement factor (\%) of the WSPC in relation to the PN reference. Labels depict the impact resistancés magnitude of the WPSC. In general, embedding the woven reinforcements improved the impact properties of WSPC as compared to the PN matrix reference. The PU-P(0)-15 sample showed the highest improvement in impact strength (55\%), whereas the PU-S(90)-20, displayed the weakest impact resistance, lower than the $\mathrm{PN}$ reference.

The causes of WSPC impact failure can be related to the distribution of compression and tensile stresses along the test sample during the Izod impact experiments. According to the mechanical theory of material [30], while a beam is bent within the elastic range, the beam bends so that the inner surface is in compression and the outer surface is in tension. Moreover, at the neutral plane, the material of the beam is not under stress, either compression or tension. The Izod impact test is performed so that the beam test sample is rapidly bent. A parametric study on tensile and compression stiffness of the woven reinforcements can provide a logical explanation on how either sides of the neutral plane, in a beam test sample, tolerate the tensile and compression stresses. Therefore, the better impact properties of the plain reinforced WSPC can be connected to the higher tensile (Table 4) and compression

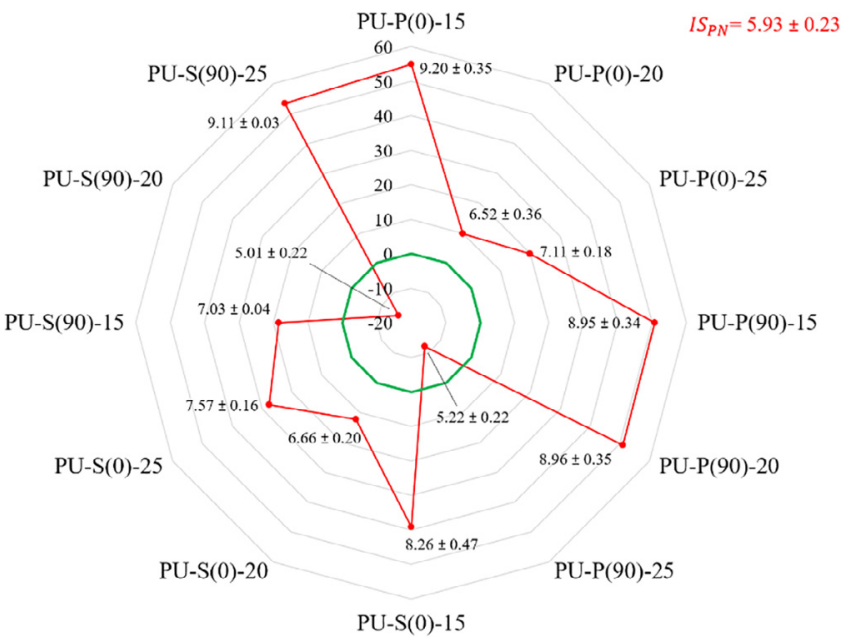

Fig. 4. Planar Izod Impact resistance improvement factors of unidirectional WSPC with woven architecture, fiber content and laminate orientation. Labels present the impact resistance (IS) data of each sample. The inner green orbit with 0 index represents the reference value. For sample designation see Table 2. stiffness (Fig. 3) of plain reinforcements as compared to the satin ones.

\subsection{Parametric study on fracture mechanism of WSPC}

\subsubsection{Finite element analysis of reinforcements}

To better explain the influence of reinforcement architecture on tensile properties of WSPC, the stress distribution through subelements of the $15 \times 15 \mathrm{~mm}$ real size 3D plain and satin structures is illustrated in Fig. 5 and Fig. 6, via finite element analysis. The boundary conditions were assigned wherein planes of $\mathrm{A}_{3}$ and $\mathrm{A}_{4}$ were considered free. The plane $A_{1}$ was restrained merely in the $\mathrm{Y}$ direction and a tensile displacement of $2 \mathrm{~mm}(\varepsilon=5 \%)$ was imposed on the plane $A_{2}$, in opposite direction. The stresses were represented by a stress tensor containing 6 components. To express these components in one value, the von Mises equivalent stress was computed. As it can be seen in Fig. 5a-b the von Mises stresses are highly concentrated at the interlacing areas.

The von Mises stress distribution through satin reinforcement in the two principal directions and at the same boundary condition is represented in Fig. 6a-b. As it can be seen in inset of Fig. 6a-b, satin structures distribute better the stresses than plain reinforcements while straining is applied in the weft direction. Due to the effect of Poisson's ratio, satin reinforcements are conteracted inward which buckles the entire reinforcement's structure. The longer float yarn is, the more buckling happens. Therefore, satin reinforcements buckles more while the tensile loads are applied in weft direction which is resulted from longer warṕs float filaments than wefts (Table 3). To release the effect of buckling, stresses are concentrated more at the interlacing areas in satin structure [31] causing better tolerating the tensile loads in either direction ( $17 \%$ and $108 \%$, respectively). As a conclusion, lower tensile stiffness of satin reinforced WSPC can be associated to the unbalanced stress distribution in structural elements of reinforcements with satin architecture (Fig. 6a-b).

\subsubsection{Image analysis of matrix-reinforcement interface}

The effect of the reinforcements structure on the fracture surface of WSPC was investigated using image processing techniques. To evaluate the matrix and reinforcement bonding state, the SEM cross-sectional fractographs of the tensile tested PU-P(0)-15 and PU-S(0)-15 samples were imported to MATLAB ${ }^{\circ}$ software to be converted into greyscale images (Fig. 7a-b). Then, the matrix data of images, ( $\mathrm{X}$ and $\mathrm{Y}$ pixels), as well as, gray level ( $\mathrm{Z}$ level) were extracted and their contour graphs were plotted. To analyze the tensile stresses distribution at the plane of stress, color segmentation of the contour plots, shown in Fig. 7c, was carried out to partition the area of $\mathrm{Z}$ level into five divisions such as $0-60,60-90,90-120,120-150$ and 150-180 ranges which were adequate for analysis precision. Subsequently, image enhancement techniques were applied to modify the object edges distance via morphological operations on binary images. The area of $\mathrm{Z}$ level, at the determined ranges, is plotted in Fig. $7 \mathrm{~d}$. In case of plain reinforced WSPC, the higher discrepancies between the area of $\mathrm{Z}$ levels is observed. Thus, it can be deduced that the stepwise configuration at fracture surface of the plain reinforced WSPC can be justified by gliding monofilaments from matrix component at the plane of stress. As a result, better tensile behavior of WSPC reinforced with the plain structures are explained (see Table 4).

At the plane of stress of WSPC, the tensile stresses can be resolved into the sum of three principal stresses including normal $\left(\sigma_{n}\right)$, transverse $\left(\sigma_{t}\right)$ and perpendicular $\left(\sigma_{p}\right)$ stresses (Fig. 8a). The external and internal stresses have the same value in an elastic mode. After the yield point this equilibrium is distorted. Therefore, the effect of filaments' aspect ratio on stress distribution at straining becomes crucial. As Fig. 8a shows, the weft filaments depicted higher aspect ratio than the warp ones. Accordingly, the stresses are applied on the weft filaments at the plane of stress while the tensile loads are exerted on the warp filaments. Hence, stresses are evenly distributed across the fractured surface of WSPC because of higher weft filaments aspect ratio. On the other hand, 


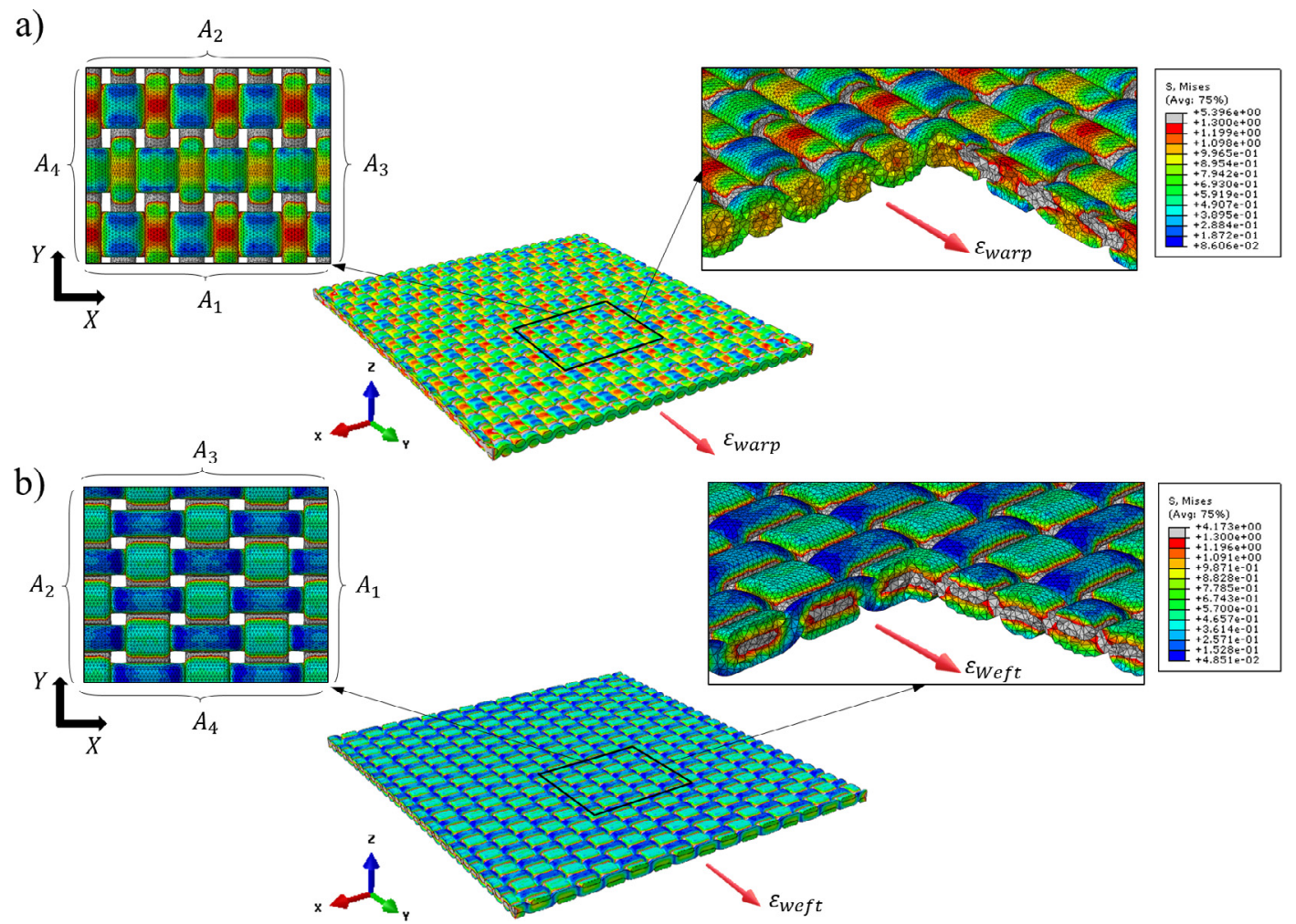

Fig. 5. Distribution of von Mises stress through subelements (filaments) of plain structure while the reinforcements are strained (5\%) in a) Warp; b) Weft directions.
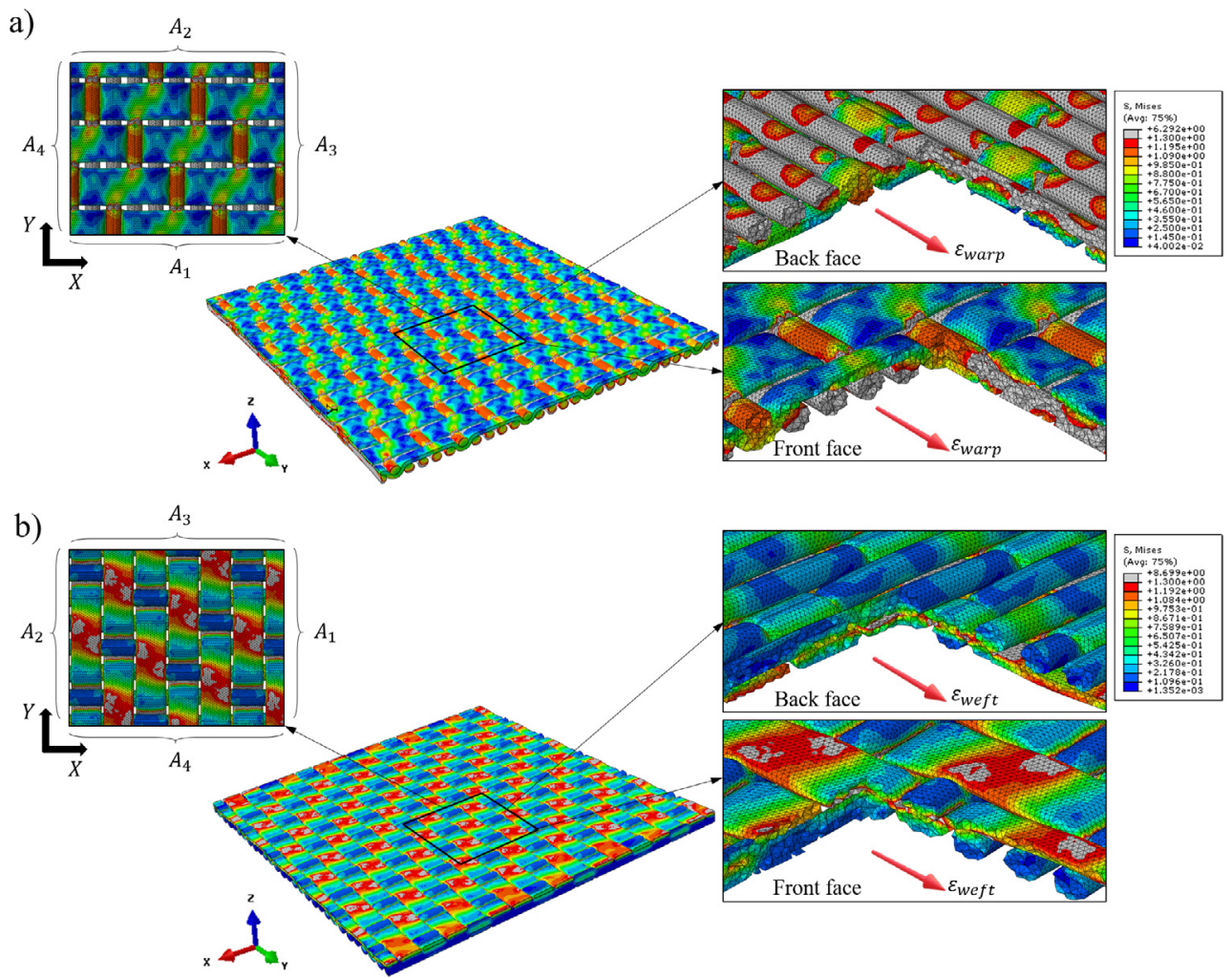

Fig. 6. Distribution of von Mises stress through subelements of satin structure at $5 \%$ straining in a) Warp; b) Weft directions.

while the tensile forces are applied in the weft direction, the stresses are imposed in the lower aspect ratio warp filaments causing higher localization of stresses at interlacing area. Therefore, the stress distribution along sub-elements (filaments) of the woven reinforcements can be logicly related with dimensional analysis of filament's aspect ratio at the plane of stress of WSPC (Fig. 8a-c).

To measure the aspect ratio of embedded filaments, the image analysis techniques were used on cross-sectional cryofracture 


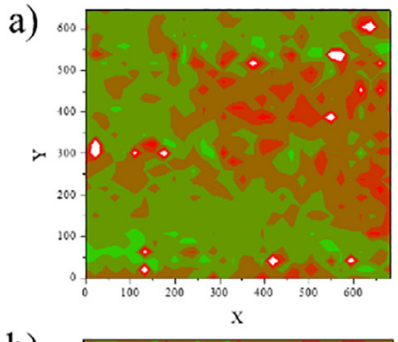

b)

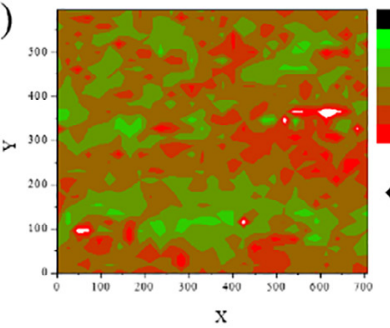

c)

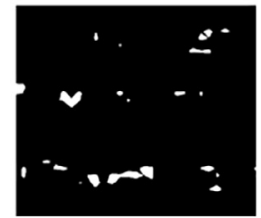

$0-60$
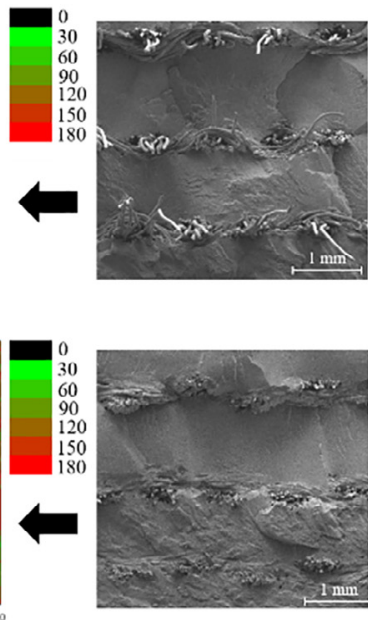

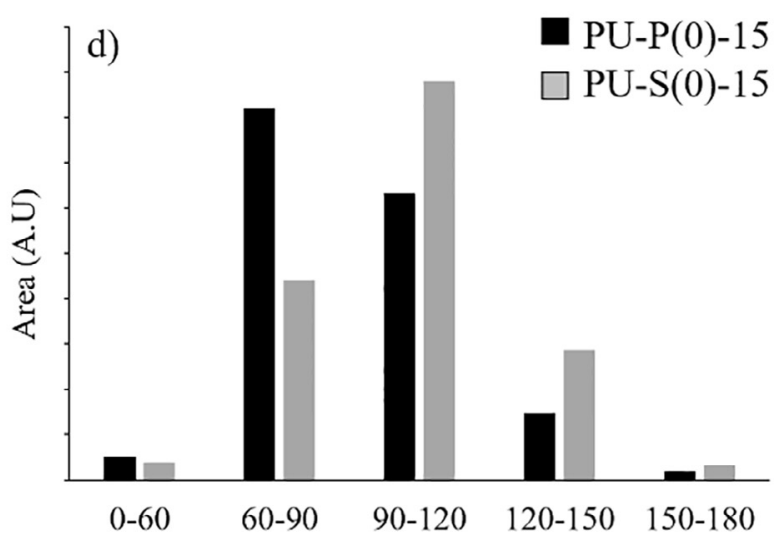

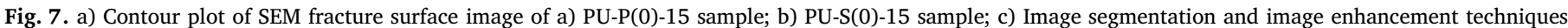

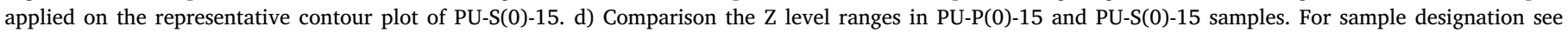
Table 2 .

microscopic images of WSPC in two principal directions using MATLAB ${ }^{\circ}$ program. As it can be seen in Fig. $8 \mathrm{~b}$, the warp and weft filament's cross-section are transformed from circular to an elliptical configuration. The major and minor axis of warp and weft monofilaments bundles were indexed by $a_{i}$ and $b_{i}$ in which the appendixes 1 and
2 are designated for warp and weft filament respectively (Fig. 8b).

As it can be seen in Fig. 8c, the embedded filaments in S-A reinforced WSPC with 20 and $25 V_{\mathrm{f}}$ have relatively identical aspect ratio in either direction although, the superior aspect ratio in the ones with $15 \%$ fiber content was in favor of weft filaments. Thus, greater aspect a)

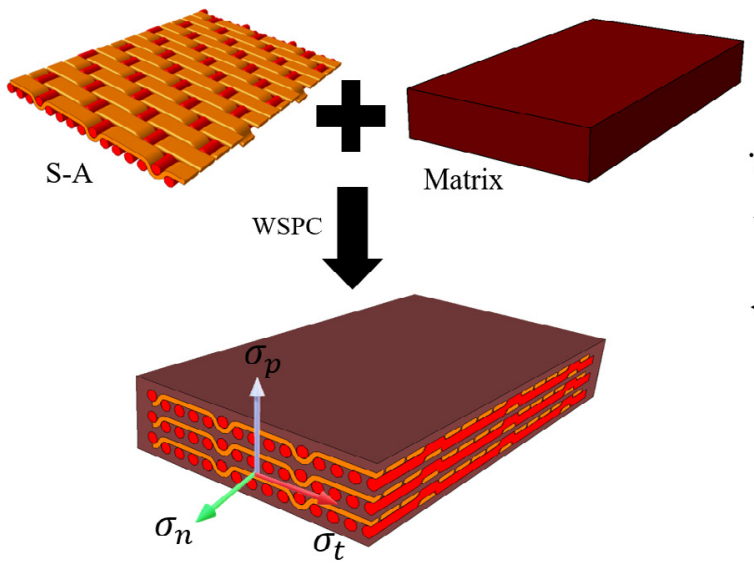

b)
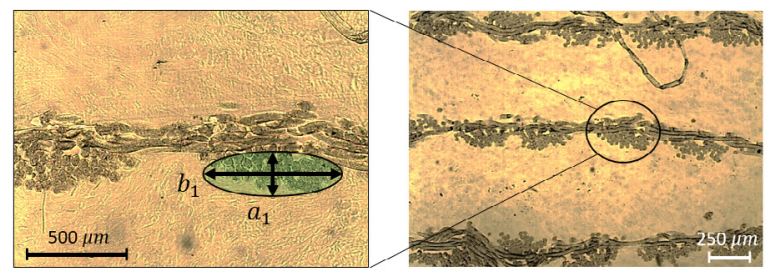

Warp cross section

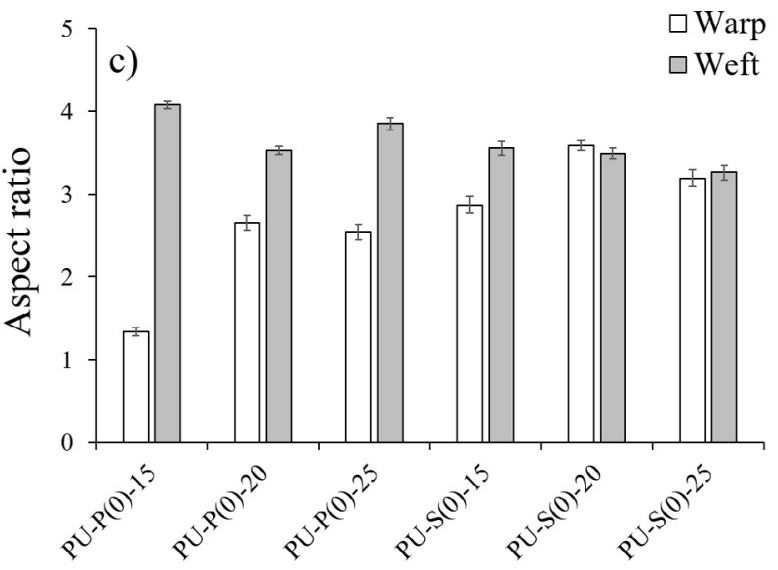

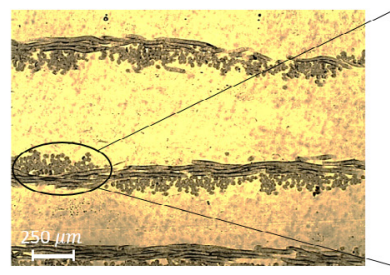

Weft cross section

Fig. 8. a) Illustrative stress distribution at the plane of stress; b) Microscopic image capturing of composite cross-section and measuring the aspect ratio of embedded filaments in two principal directions; c) comparison on aspect ratio of embedded warp and weft filaments in WSPC with different fiber content. For sample designation see Table 2 . 
ratio of weft filaments in later case is caused better distribution of stresses while the tensile loads are applied in warp direction. Consequently, the better tensile behavior of warp-wise WSPC reinforced with S-A can be explained (see Table 4). In case composites reinforced with P-A structures, a significant difference between the warp and weft filaments aspect ratio is observed. As Fig. 8c shows, in case plain reinforced WSPC, the differences between warp and weft filament's aspect ratio is minimized while the fiber content increases. Due to this observation, the better tensile properties in weft-wise composites with higher ply number is predicted. Moreover, the stresses are distributed better at the surface fracture of warp-wise P-A reinforced WSPC due to the higher aspect ratio of embedded weft filaments. The lowest tensile properties of PU-P(90)-15 sample can be attributed with the bottommost aspect ratio of warp filaments which raise the stress concentration at interlacing area while the tensile loads are applied in weft direction (see Table 4).

\section{Conclusions}

Woven reinforced PA6 based single polymer composites (WSPC) were produced by combination of powder-coating and compression molding techniques (PCCM). Plain and satin weave patterns were used as reinforcements. The mechanical and geometrical properties of all woven reinforcements were improved and stabilized by a stretchingannealing treatment. The microparticles (MP) used in the matrix were synthesized by solution-precipitation AAROP. The influence of reinforcement architecture, fiber volume fraction and reinforcement orientation on the final tensile properties of WSPC was evaluated. A parametric study via finite element analysis was performed to relate the effect of woven reinforcement geometry, with the overall mechanical properties of WSPC. Moreover, image processing techniques were used to investigate the bonding state at the interface region and then correlate with overall tensile properties of WSPC. Based on the study performed, the following conclusions can be drawn:

i) The plain reinforced WSPC demonstrated more isotropic tensile properties and better impact strength than those reinforced with the satin structures due to the higher tensile and compression stiffness.

ii) The finite element analysis showed that the von Mises stresses were evenly distributed through the fabric subelements in the plain reinforcement which led to the better tensile and impact properties of plain reinforced WSPC.

iii) The parametric finite element analysis showed that the filaments in the satin structures had higher tolerance to tensile loads, $17 \%$ and $108 \%$ in warp and weft directions, respectively, as compared to the plain ones. However, these reinforcements buckled more due to the existence of float filaments in their structure, causing an increase of stress concentration at the interlacing areas and uneven stress distribution along the reinforcement's subelements.

iv) The better tensile and impact properties of plain reinforced WSPC (particularly in warp direction) were also justified using image processing of the composite's surface fracture. The difference between the gray level areas together with the higher indentation on the surface fracture in plain reinforced composites proved the gliding of the monofilaments through the matrix component, which is the main responsible for the better mechanical properties.

v) The slightly equal aspect ratio of the filaments in the satin reinforced WSPC, could explain the even distribution of the stresses at the plane of stress in either direction. This can be linked to the similiar tensile properties in the warp and weft directions of these composites.

\section{Acknowledgments}

This work was partially financed by FEDER funds through the
COMPETE program and by national funds through FCT - Foundation for Science and Technology within the project POCI-01-0145-FEDER007136. SDT thanks FCT for his PhD Grant SFRH/BD/94759/2013. NVD thanks for the financial support of FCT through the strategic project UID/CTM/50025/2013. ZZD is thankful to FCT for the SFRH/ $\mathrm{BSAB} / 130271 / 2017$ personal research grant. All authors acknowledge the support of the project TSSiPRO-NORTE-01-0145-FEDER-000015 funded by the regional operational program NORTE 2020, under the PORTUGAL 2020 Partnership Agreement, through the European Regional Development Fund.

\section{References}

[1] Matabola KP, Vries AR, Moolman FS, Luyt AS. Single polymer composites: a review. J Mater Sci 2009;44:6213-22.

[2] Yao D, Li R, Nagarajan P. Single-polymer composites based on slowly crystallizing polymers. Polym Eng Sci 2006;46:1223-30.

[3] La Mantia FP, Curto D, Scaffaro R. Recycling of dry and wet polyamide 6. J Appl Polym Sci 2002;86:1899-903.

[4] Lacroix Fv, Werwer M, Schulte K. Solution impregnation of polyethylene fibre/polyethylene matrix composites. Compos Part A Appl Sci Manuf 1998;29:371-6.

[5] Hine PJ, Astruc A, Ward IM. Hot compaction of polyethylene naphthalate. J Appl Polym Sci 2004;93:796-802.

[6] Ward IM, Hine PJ. The science and technology of hot compaction. Polymer (Guildf) 2004;45:1413-27.

[7] Gong Y, Yang G. Single polymer composites by partially melting recycled polyamide 6 fibers: preparation and characterization. J Appl Polym Sci 2010;118:3357-63.

[8] Alcock B, Cabrera NO, Barkoula N-M, Wang Z, Peijs T. The effect of temperature and strain rate on the impact performance of recyclable all-polypropylene composites. Compos Part B Eng 2008;39:537-47.

[9] Bhattacharyya D, Maitrot P, Fakirov S. Polyamide 6 single polymer composites. Express Polym Lett 2009;3:525-32.

[10] Dencheva N, Denchev Z, Pouzada AS, Sampaio AS, Rocha AM. Structure-properties relationship in single polymer composites based on polyamide 6 prepared by in-mold anionic polymerization. J Mater Sci 2013;48:7260-73.

[11] Tohidi SD, Rocha AM, Dencheva NV, Denchev Z. Single polymer laminate composites by compression molding of knitted textiles and microparticles of polyamide 6: preparation and structure-properties relationship. Compos Part A Appl Sci Manuf 2018;109:171-83.

[12] Júnior CZP, De Carvalho LH, Fonseca VM, Monteiro SN, d'Almeida JRM. Analysis of the tensile strength of polyester/hybrid ramie-cotton fabric composites. Polym Test 2004;23:131-5.

[13] Mariatti M, Nasir M, Ismail H. Influence of different woven geometry and ply effect in woven thermoplastic composite behaviour-Part 2. Int J Polym Mater 2000;47:499-512.

[14] Osada T, Nakai A, Hamada H. Initial fracture behavior of satin woven fabric composites. Compos Struct 2003;61:333-9.

[15] Asi O. Effect of different woven linear densities on the bearing strength behaviour of glass fiber reinforced epoxy composites pinned joints. Compos Struct 2009;90:43-52.

[16] Lomov SV, Ivanov DS, Truong TC, Verpoest I, Baudry F, Vanden Bosche K, et al. Experimental methodology of study of damage initiation and development in textile composites in uniaxial tensile test. Compos Sci Technol 2008;68:2340-9.

[17] Pandita SD, Huysmans G, Wevers M, Verpoest I. Tensile fatigue behaviour of glass plain weave fabric composites in on-and off-axis directions. Compos Part A Appl Sci Manuf 2001;32:1533-9.

[18] Ravandi M, Teo WS, Tran LQN, Yong MS, Tay TE. Low velocity impact performance of stitched flax/epoxy composite laminates. Compos Part B Eng 2017;117:89-100.

[19] Taraghi I, Fereidoon A, Taheri-Behrooz F. Low-velocity impact response of woven Kevlar/ epoxy laminated composites reinforced with multi-walled carbon nanotubes at ambient and low temperatures. Mater Des 2014;53:152-8.

[20] Lei X, Rui W, Shujie Z, Yong L. Vibration characteristics of glass fabric/epoxy composites with different woven structures. J Compos Mater 2011;45:1069-76.

[21] Houshyar S, Shanks RA, Hodzic A. Influence of different woven geometry in poly (propylene) woven composites. Macromol Mater Eng 2005;290:45-52.

[22] Stig F, Hallström S. Influence of crimp on 3D-woven fibre reinforced composites. Compos Struct 2013;95:114-22.

[23] Potluri P, Thammandra VS. Influence of uniaxial and biaxial tension on meso-scale geometry and strain fields in a woven composite. Compos Struct 2007;77:405-18.

[24] Brêda C, Dencheva N, Lanceros-Méndez S, Denchev Z. Preparation and properties of metal-containing polyamide hybrid composites via reactive microencapsulation. J Mater Sci 2016;51:10534-54.

[25] Dencheva N, Denchev Z, Lanceros-Méndez S, Ezquerra Sanz T. One-step in situ synthesis of polyamide microcapsules with inorganic payload and their transformation into responsive thermoplastic composite materials. Macromol Mater Eng 2016;301:119-24.

[26] Menard KP. Dynamic mechanical analysis: a practical introduction. CRC Press; 2008.

[27] Saba N, Jawaid M, Sultan MTH. An overview of mechanical and physical testing of composite materials. Mech. Phys. Test. Biocomposites, Fibre-Reinforced Compos. Hybrid Compos. Elsevier; 2019. p. 1-12.

[28] Kemp A. An extension of Peirce's cloth geometry to the treatment of non-circular threads. J Text Inst 1958;44-48.

[29] Zienkiewicz OC, Taylor RL, Zienkiewicz OC, Taylor RL. The finite element method. London: McGraw-hill; 1977.

[30] Dowling NE. Mechanical behavior of materials. Virginia: Pearson Prentice Hall; 2012.

[31] Zhang YT, Fu YB. A micromechanical model of woven fabric and its application to the analysis of buckling under uniaxial tension: Part 1: The micromechanical model. Int J Eng Sci 2000;38:1895-906. 